\title{
DETERMINAN NIAT PEMBELIAN PRODUK WARDAH DI JAKARTA
}

\author{
Vera Laviana ${ }^{1}$, Cokki $^{2}$ \\ ${ }^{1}$ Program Studi Manajemen, Fakultas Ekonomi dan Bisnis, Universitas Tarumanagara \\ Email:vera.115170226@stu.untar.ac.id \\ ${ }^{2}$ Program Studi Manajemen, Fakultas Ekonomi dan Bisnis, Universitas Tarumanagara* \\ Email:cokki@fe.untar.ac.id
}

*Penulis Korespondensi

Masuk : 02-08-2021, revisi: 15-08-2021, diterima untuk diterbitkan : 30-08-2021

\begin{abstract}
ABSTRAK
Tujuan dari penelitian ini adalah untuk menguji pengaruh religiusitas terhadap niat pembelian melalui gaya hidup dan sikap. Sampel dari penelitian ini melibatkan 150 responden wanita yang menggunakan produk Wardah di Jakarta, yang dipilih dengan menggunakan convenience sampling. Data diambil dengan menggunakan kuesioner secara online dan diolah menggunakan Partial Least Square-Structural Equation Modeling (PLS-SEM). Hasil dari penelitian ini adalah religiusitas hanya dapat mempengaruhi niat pembelian secara tidak langsung melalui gaya hidup dan sikap. Gaya hidup mempengaruhi niat pembelian secara langsung maupun secara tidak langsung melalui sikap dan sikap dapat mempengaruhi niat pembelian.
\end{abstract}

Kata Kunci: Religiusitas, Gaya Hidup, Sikap, Niat Pembelian

\section{ABSTRACT}

The purpose of this study was to examine the effect of religiosity on purchase intentions through lifestyle and attitudes. The sample of this study involved 150 female respondents who used Wardah products in Jakarta, which were selected using convenience sampling. Data were taken using a bold questionnaire and processed using Partial Least Square-Structural Equation Modeling (PLS-SEM). The result of this study is that religiosity can only affect purchase intentions indirectly through lifestyle and attitudes. Lifestyle affects purchase intentions directly or indirectly through attitudes and attitudes can affect purchase intentions.

Keywords: Religiosity, Lifestyle, Attitude, Purchase Intention

\section{PENDAHULUAN}

\section{Latar Belakang}

Persaingan antar pasar industri kosmetik yang semakin kompetitif, yang dibuktikan dengan banyaknya kosmetik yang beredar baik diproduksi dalam negeri maupun luar negeri sehingga pemerintah mengambil langkah untuk menuntut produsen kosmetik dalam negeri agar dapat memenuhi selera dan kebutuhan konsumen. Salah satu perusahaan lokal di Indonesia adalah PT Paragon Technology and Innovation yang berdiri pada tanggal 28 Februari 1985. Perusahan ini memproduksi haircare, skincare, dan kosmetik dengan brand sendiri, seperti Wardah (Wardah, 2020).

Wardah menjadi salah satu kosmetik yang memiliki ciri khas yaitu adalah kosmetik halal pertama di Indonesia, yang pada dasarnnya target utama produk Wardah adalah wanita muslim yang ingin menggunakan kosmetik, namun seiring berkembangnya waktu produk Wardah sekarang meluas ke semua wanita. Wardah juga memiliki tantangan dan tanggung jawab yang besar untuk menciptakan produk dengan inovasi-inovasi yang terbaru sehingga dapat memenuhi gaya hidup konsumennya yang semakin modern dan mepertahankan kualitas produknya dengan 
harapan bahwa konsumen dapat menyukai produknya sehingga meningkatkan niat pembelian individu.

Berdasarkan penelitian terdahulu (Muhamad dkk., 2017; Chen, 2009; Tuhin dkk., 2020; Rizkitysha \& Hananto, 2020) yang meneliti tentang makanan, kosmetik, dan deterjen yang dilakukan di negara Malaysia, Brunei, Thailand dengan menggunakan variabel religiusitas, gaya hidup, sikap dan niat pembelian. Namun belum ada yang meneliti tentang produk Wardah di Jakarta dengan menggabungkan seluruh variabel tersebut dalam satu penelitian, sehingga penelitian ini dilakukan agar dapat mengetahui seberapa besar pengaruh dan hubungan antara religiusitas, gaya hidup, dan sikap konsumen yang akan meningkatkan niat pembelian pada produk Wardah.

\section{Kajian teori}

Penelitian ini mengacu pada teori Teori Perilaku Direncanakan (Theory of Planned Behavior) yang dikembangkan oleh Azjen (1991), karena fokus utama dalam teori ini ialah niat individu untuk melakukan perilaku tertentu. Niat adalah indikasi seberapa kerasnya seseorang berusaha untuk mencoba dan berapa besar usaha yang dilakukan individu untuk melakukan suatu perilaku. Menurut Fishbein dan Ajzen (1977) juga mengatakan bahwa niat membeli mengacu pada individu untuk memperoleh produk dan merupakan aspek penting dalam mengukur perilaku konsumen. Salah satu cara untuk mengetahui perilaku konsumen yaitu dengan cara mengukur sikap seseorang terhadap objek di sekitar perilaku pembelian, semakin positif sikap seseorang maka semakin besar juga niatnya dengan demikian hal ini terlihat dalam perilaku keputusan pembelian dan sebaliknya.

\section{Religiusitas}

Religiusitas merupakan kepercayaan kepada Tuhan dengan mematuhi prinsip-prinsip yang telah di tetapkan olehNya (Bakar dkk., 2013). Dan berperilaku sesuai dengan ajaran agamaNya dan menghindari tindakan-tindakan negatif (Baatwah dkk., 2020). Maka berdasarkan definisi diatas dapat disimpulkan bahwa religiusitas adalah komitmen seseorang terhadap agama dan menghindari tindakan negatif sesuai dengan ajaran agamanya.

\section{Gaya hidup}

Gaya hidup merupakan gambaran perilaku seseorang yang dapat dilihat dari bagaimana kehidupanya, saat menggunakan uang dan memanfaatkan waktu (Amri \& Prihandono, 2019). Gaya hidup dapat ditentukan oleh pengalaman masa lalu, karakteristik bawaan dan keadaan saat ini (Selvakumar \& Raghavan, 2017). Sehingga gaya hidup dapat dikatakan sebagai gambaran pola hidup seseorang saat menggunakan uang dan waktunya untuk memenuhi kebutuhan yang dapat berubah sesuai perkembangan zaman.

\section{Sikap}

Sikap dapat dikatakan sebagai evaluasi umum seseorang terhadap sesuatu (Cokki dkk., 2019), yang dapat berupa perasaan positif atau negatif seseorang pada suatu produk atau jasa (Hoque dkk., 2018). Maka berdasarkan definisi diatas dapat disimpulkan bahwa sikap adalah cara individu dalam merespon suatu objek tertentu yang dapat dinilai secara positif atau negatif.

\section{Niat pembelian}

Menurut Keni dkk. (2019) niat sangat erat hubungannya dengan perikatan, yaitu janji yang akan dipenuhi pada tempat dan waktu tertentu. Niat pembelian merupakan janji kepada diri sendiri dan mewakili apa yang ingin dibeli di masa depan (Tariq dkk., 2013; Lin \& Lu, 2010). Sehingga 
dapat disimpulkan bahwa niat pembelian adalah keinginan sesorang untuk melakukan pembelian produk atau jasa pada waktu tertentu.

\section{Kaitan antar Variabel Religiusitas, Gaya Hidup, Sikap dan Niat Pembelian}

Dalam penelitian Muhamad dkk. (2017) yang meneliti tentang makanan dalam kemasan, dan Rizkitysha \& Hananto (2020) tentang deterjen yang berlebel halal, serta penelitian yang dilakukan oleh Memon dkk. (2020) di Pakistan yang memiliki hasil bahwa religiusitas memiliki pengaruh positif terhadap niat pembelian. Kemudian terdapat hasil penelitian bahwa religiusitas memilik pengaruh yang positif terhadap sikap dalam penelitian (Tuhin dkk., 2020) dan Widyanto \& Sitohang (2021) tentang penggunaan kosmetik halal, serta penelitian yang dilakukan oleh Ngah dkk. (2021). Selanjutnya religiusitas juga memiliki pengaruh yang positif terhadap gaya hidup yang didukung oleh penelitian Rashidi (2015) tentang gaya hidup perempuan di Iran, penelitian Tey (2018), dan yang terakhir penelitian Nora \& Minati (2016) dalam menggunakan hijab.

Tangsupwattana \& Liu (2017) penelitian ini dilakukan di Thailand pada konsumen generasi y, dan penelitian Basha dkk. (2015), serta Putri (2019) tentang niat pembelian di cafe. Dalam ketiga penelitian tersebut terdapat hasil penelitian yaitu gaya hidup memiliki pengaruh yang positif terhadap niat pembelian. Kemudian gaya hidup juga memiliki pengaruh yang positif terhadap sikap, yang didukung oleh penelitian Silva dkk. (2016) tentang pembelian makanan melalui internet, dan Chen (2009), serta Tangsupwattana \& Liu (2017) pada konsumen generasi y di Thailand.

Dalam penelitian Suki (2016) tentang produk ramah lingkungan yang dilakukan di Malaysia, yang menyatakan bahwa sikap memiliki pengaruh yang positif terhadap niat pembelian. Sama halnya dengan penelitian Rezai dkk. (2017) yang juga dilakukan di Malaysia tentang makanan fungsional, serta Souiden \& Rani (2015) dalam menggunakan jasa bank Syariah.

Berdasarkan kaitan variabel diatas, maka model penelitian ini sebagai berikut:

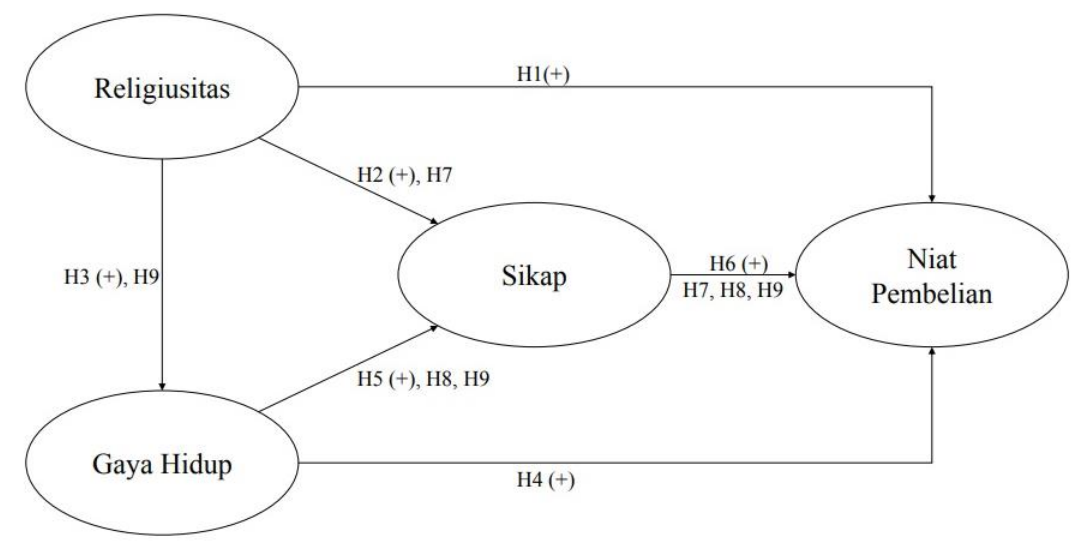

Gambar 1. Model penelitian

Hipotesis dalam penelitian ini adalah sebagai berikut:

$\mathrm{H}_{1}$ : Religiusitas memiliki pengaruh yang positif terhadap niat pembelian.

$\mathrm{H}_{2}$ : Religiusitas memiliki pengaruh yang positif terhadap sikap.

$\mathrm{H}_{3}$ : Religiusitas memiliki pengaruh yang positif terhadap gaya hidup.

$\mathrm{H}_{4}$ : Gaya hidup memiliki pengaruh yang positif terhadap niat pembelian.

$\mathrm{H}_{5}$ : Gaya hidup memiliki pengaruh yang positif terhadap sikap. 
$\mathrm{H}_{6}$ : Sikap memiliki pengaruh yang positif terhadap niat pembelian.

$\mathrm{H}_{7}$ : Religiusitas memiliki pengaruh yang positif terhadap niat pembelian melalui sikap.

$\mathrm{H}_{8}$ : Gaya Hidup memiliki pengaruh yang positif terhadap niat pembelian melalui sikap.

$\mathrm{H}_{9}$ : Religiusitas memiliki pengaruh yang positif terhadap niat pembelian melalui gaya hidup dan sikap.

\section{METODE PENELITIAN}

Penelitian ini menggunakan jenis penelitian deskriptif dengan menggunakan data cross-sectional design, karena peneliti hanya mengumpulkan informasi dengan mengambil sampel tertentu dari elemen populasi dan hanya dilakukan satu kali saja kepada responden (Malhotra, 2015)

Teknik pengumpulan data dengan menyebarkan kuesioner yang berskala likert 1 (sangat tidak setuju) - 5 (sangat setuju). Variabel religiusitas diukur dengan menggunakan 7 indikator, yaitu keyakinan agama penting, membaca yang berhubungan dengan agama, memiliki pengetahuan agama yang cukup, meluangkan waktu memahami agama, sedih saat melalukan sesuatu yang bertentangan, kewajiban agama menjadi pertimbangan utama dalam membeli barang (Rostiani dkk., 2021; Widyanto \& Sitohang, 2021; Alsaad dkk., 2020). Variabel gaya hidup diukur dengan menggunakan 6 indikator, yaitu wajib membeli produk saat mempunyai uang, untuk memuaskan diri, sering dipengaruhi oleh iklan, selalu mencoba produk terbaru dan untuk mendukung penampilan (Yang, 2004; Tangsupwattana \& Liu, 2017; Lee, 2017). Sikap diukur dengan menggunakan 6 indikator, yaitu reputasi yang baik, merasa cocok, pilihan diri sendiri, bermanfaat untuk penampilan, memenuhi harapan (Rizkitysha \& Hananto, 2020; Cheah dkk., 2021; Kudeshia \& Kumar, 2017). Niat pembelian diukur dengan menggunakan 5 indikator, yaitu memilih produk tersebut, tanpa banyak pertimbangan, membeli produk yang pernah digunakan, membeli saat membutuhkan dan dalam waktu dekat (Watson dkk., 2018; Ustaahmetoglu, 2020; Kudeshia \& Kumar, 2017).

Teknik analisis data yang digunakan adalah Partial Least Square-Structural Equation Modeling (PLS-SEM) dan diolah dengan alat SmartPLS. Teknik uji statistic dalam penelitian ini terdiri dari uji validitas dan uji reliabilitas dan teknik analisis data yang digunakan yaitu uji multilolinearitas (VIF), uji koefisien determinasi $\left(R^{2}\right)$, uji predictive relevance $\left(Q^{2}\right)$, uji effect $\operatorname{size}\left(F^{2}\right)$, uji path coefficients, dan pengujian hipotesis ( $p$-value).

\section{HASIL DAN PEMBAHASAN}

Pada penelitian ini melibatkan 150 responden wanita, dengan rentang usia yang lebih mendominasi yaitu 19-23 tahun berjumlah 129 orang responden (86\%). Selanjutnya pada kategori pekerjaan yang lebih mendominasi adalah pelajar/mahasiswa dengan jumlah 115 orang responden $(76 \%)$ dan sebagian besar memiliki pendapatan perbulan kurang dari 1.500 .000 yaitu sebanyak 76 orang (50\%). Selanjutnya, mayoritas responden dalam penelitian ini memeluk agama katolik sebanyak 49 orang $(32 \%)$.

Sebagian besar responden memiliki tingkat religiusitas dan gaya hidup yang tinggi. Mayoritas responden memiliki sikap yang positif dan mempunyai keinginan untuk membeli yang besar.

\section{Validitas}

Setiap variabel pada penelitian ini telah lolos uji validitas konvergen karena memiliki nilai AVE lebih dari 0.5 (Hair dkk., 2019; Tabel 1) dan hasil uji validitas diskriminan dinyatakan lolos karena memiliki nilai Heterotrait-Monotrait Ratio (HTMT) kurang dari 0.9 (Hair dkk., 2019; Tabel 2). Maka keempat variabel dalam penelitian ini telah memenuhi syarat. 
Tabel 1. Hasil Uji Validitas Konvergen

\begin{tabular}{|c|c|}
\hline Variabel & Average Variance Extracted (AVE) \\
\hline Religiusitas & 0.517 \\
\hline Gaya Hidup & 0.777 \\
\hline Sikap & 0.713 \\
\hline Niat Pembelian & 0.615 \\
\hline
\end{tabular}

Tabel 2. Hasil Uji Validitas Diskriminan

\begin{tabular}{|l|c|c|c|}
\hline \multicolumn{1}{|c|}{ Variabel } & Gaya Hidup & Niat Pembelian & Religiusitas \\
\hline Niat Pembelian & 0.895 & & \\
\hline Religiusitas & 0.516 & 0.449 & \\
\hline Sikap & 0.750 & 0.894 & 0.500 \\
\hline
\end{tabular}

\section{Reliabilitas}

Hasil uji reliabilitas indikator menunjukkan bahwa setiap indikator valid, sehingga seluruh indikator dapat digunakan dalam penelitian ini, karena nilai loading factor telah lolos uji dengan memiliki nilai diatas 0.5 (Ghozali, 2014; Tabel 3) dan hasil uji reliabilitas konsistensi internal menunjukkan bahwa setiap indikator yang digunakan sudah reliabel dan dapat diandalkan karena memiliki nilai composite reliability lebih dari 0.7 (Hair dkk., 2019; Tabel 4).

Tabel 3. Hasil Uji Reliabilitas Indikator

\begin{tabular}{|c|c|c|c|c|c|c|c|c|c|}
\hline \multicolumn{3}{|c|}{ Religiusitas } & \multicolumn{2}{c|}{ Gaya Hidup } & \multicolumn{2}{c|}{ Sikap } & \multicolumn{2}{c|}{ Niat Pembelian } \\
\hline R1 & 0.634 & R5 & 0.846 & GH1 & 0.875 & S1 & 0.809 & NP2 & 0.823 \\
\hline R2 & 0.783 & R6 & 0.572 & GH3 & 0.849 & S2 & 0.778 & NP3 & 0.798 \\
\hline R3 & 0.711 & R7 & 0.670 & GH4 & 0.892 & S5 & 0.877 & NP4 & 0.672 \\
\hline R4 & 0.780 & & & GH5 & 0.908 & S6 & 0.908 & NP5 & 0.832 \\
\hline
\end{tabular}

Tabel 4. Hasil Uji Reliabilitas Konsistensi

\begin{tabular}{|l|c|}
\hline \multicolumn{1}{|c|}{ Variabel } & Composite Reliability \\
\hline Religiusitas & 0.881 \\
\hline Gaya Hidup & 0.933 \\
\hline Sikap & 0.908 \\
\hline Niat Pembelian & 0.864 \\
\hline
\end{tabular}

\section{Multikoliniearitas}

Hasil uji multikoliniearitas yang dilihat dari nilai variance inflation factor (VIF) kurang dari 5 maka dapat dikatakan penelitian ini baik karena tidak terdapat multikoliniearitas antar variabel bebas (Hair dkk., 2019).

Tabel 5. Hasil Uji Multikoliniearitas

\begin{tabular}{|c|c|c|}
\hline Variabel & Nilai & Keterangan \\
\hline $\mathrm{NP}=\mathrm{f}(\mathrm{S}, \mathrm{R}, \mathrm{GY})$ & $\mathrm{VIF}=1.888$ & Tidak ada multikoliniearitas \\
$\mathrm{S}$ & $\mathrm{VIF}=1.343$ & Tidak ada multikoliniearitas \\
$\mathrm{R}$ & $\mathrm{VIF}=1.969$ & Tidak ada multikoliniearitas \\
$\mathrm{GY}$ & & \\
$\mathrm{S}=\mathrm{f}(\mathrm{R}, \mathrm{GY})$ & $\mathrm{VIF}=1.297$ & Tidak ada multikoliniearitas \\
$\mathrm{R}$ & $\mathrm{VIF}=1.297$ & Tidak ada multikoliniearitas \\
$\mathrm{GY}$ &
\end{tabular}

\section{Koefisien Determinasi dan Relevansi Prediksi}

Pada hasil uji koefisiensi determinasi terlihat kemampuan yang sedang untuk menjelaskan variabel niat pembelian, karena nilainya berada diantara 0.50 dan 0.75 . Kemudian kemampuan 
yang kecil untuk menjelaskan variabel sikap karena nilainya berada diantara 0.25 dan 0.50. Dan kemampuan yang sangat kecil untuk menjelaskan variabel gaya hidup, karena nilainya berada berada dibawah 0.25. Selanjutnya pada uji relevansi prediksi (Tabel 6) menunjukan bahwa variabel niat pembelian dan sikap dapat memprediksi model dengan kemampuan sedang karena miliki nilai diatas 0.25 , sedangkan gaya hidup memiliki kemampuan memprediksi model yang kecil karena dibawah 0.25 (Hair dkk., 2019).

\begin{tabular}{|c|c|c|}
\hline \multicolumn{3}{|c|}{ Tabel 6. Hasil Uji Analisis $\mathrm{R}^{2}$ dan $\mathrm{Q}^{2}$} \\
\hline Variabel & $\mathbf{R}^{2}$ & $\mathbf{Q}^{2}$ \\
\hline Niat Pembelian & 0.688 & 0.314 \\
\hline Sikap & 0.470 & 0.408 \\
\hline Gaya Hidup & 0.229 & 0.167 \\
\hline
\end{tabular}

\section{Pengujian Hipotesis}

Berdasarkan hasil uji hipotesis (Tabel 7), maka dapat disimpulkan bahwa $\mathrm{H}_{3}, \mathrm{H}_{4}, \mathrm{H}_{5}, \mathrm{H}_{6}, \mathrm{H}_{8}, \mathrm{H}_{9}$ di dukung, karena memiliki nilai p-value dibawah 0.05 dan arah koefisiensinya sejalan dengan hipotesis, sedangkan $\mathrm{H}_{1}, \mathrm{H}_{2}, \mathrm{H}_{7}$ tidak didukung karena memliki nilai p-value diatas 0.5. Selanjutnya, effect size $\left(\mathrm{f}^{2}\right)$ ditentukan melalui nilai yang terbagi menjadi tiga bagian, yaitu nilai 0.02 yang dapat diartikan bahwa memiliki pengaruh yang kecil, 0.15 menunjukan bahwa memiliki pengaruh sedang dan 0.35 yang berati memiliki pengaruh yang besar (Hair dkk., 2019).

Tabel 7. Hasil Uji Hipotesis

\begin{tabular}{|l|l|c|}
\hline \multicolumn{1}{|c|}{ Hipotesis } & \multicolumn{1}{c|}{ Nilai } & Keterangan \\
\hline Religiusitas $\rightarrow$ Niat Pembelian & $\beta:-0.053$ & Negatif \\
& p-value: 0.327 & Tidak Signifikan \\
& $\mathrm{f}^{2}: 0.007$ & Efek kecil \\
\hline Religiusitas $\rightarrow$ Sikap & $\beta: 0.157$ & Positif \\
& p-value: 0.090 & Tidak Signifikan \\
& $\mathrm{f}^{2}: 0.036$ & Efek Kecil \\
\hline Religiusitas $\rightarrow$ Gaya Hidup & $\beta: 0.476$ & Positif \\
& $\mathrm{p}$-value: 0.000 & Signifikan \\
& $\mathrm{f}^{2}: 0.297$ & Efek Sedang \\
\hline Gaya Hidup $\rightarrow$ Niat Pembelian & $\beta: 0.525$ & Positif \\
& $\mathrm{p}$-value: 0.000 & Signifikan \\
& $\mathrm{f}^{2}: 0.448$ & Efek Besar \\
\hline Gaya Hidup $\rightarrow$ Sikap & $\beta: 0.597$ & Positif \\
& $\mathrm{p}$-value: 0.000 & Signifikan \\
& $\mathrm{f}^{2}: 0.518$ & Efek Besar \\
\hline Sikap $\rightarrow$ Niat Pembelian & $\beta: 0.409$ & Positif \\
& $\mathrm{p}$-value: 0.000 & Signifikan \\
& $\mathrm{f}^{2}: 0.283$ & Efek Sedang \\
\hline Religiusitas $\rightarrow$ Sikap $\rightarrow$ Niat Pembelian & $\beta: 0.075$ & Positif \\
& p-value: 0.054 & Tidak Signifikan \\
\hline Gaya Hidup $\rightarrow$ Sikap $\rightarrow$ Niat Pembelian & $\beta: 0.285$ & Positif \\
& p-value: 0.000 & Signifikan \\
\hline Religiusitas $\rightarrow$ Gaya Hidup $\rightarrow$ Sikap $\rightarrow$ Niat & $\beta: 0.136$ & Positif \\
Pembelian & p-value: 0.000 & Signifikan \\
\hline
\end{tabular}

\section{Diskusi}

Berdasarkan hasil uji hipotesis pertama, religiusitas tidak mampu mempengaruhi niat pembelian, maka dapat disimpulkan bahwa $\mathrm{H}_{1}$ tidak didukung. Hal ini tidak sejalan dengan penelitian sebelumnya (Muhamad dkk, 2019; Rizkitysha \& Hananto, 2020; Memon dkk., 2019) yang menyatakan bahwa religiusitas memiliki pengaruh yang positif terhadap niat pembelian pada 
makanan dalam kemasan dan produk halal di Pakistan dengan responden beragama muslim, berbeda halnya dengan peneltian ini yang mayoritas responden beragama non muslim, sehingga memungkinkan bahwa religiusitas yang dimiliki individu memiliki peran yang penting namun tidak dapat sepenuhnya menentukan niat pembelian termasuk pada produk Wardah.

Berdasarkan hasil uji hipotesis kedua, dapat disimpulkan bahwa $\mathrm{H}_{2}$ tidak didukung. Maka hal ini tidak sejalan dengan penelitian terdahulu (Tuhin dkk., 2020; Widyanto \& Sitohang., 2020; Ngah dkk., 2021), sehingga dapat diartikan bahwa religiusitas memiliki pengaruh yang positif terhadap sikap hanya berlaku pada beberapa penelitian saja dan tidak berlaku pada pengguna produk Wardah, karena penelitian ini mayoritas respondennya beragama non muslim maka menunjukan bahwa komitmen pelanggan terhadap keyakinan mereka saja tidak cukup untuk dapat membentuk sikap yang positif terhadap produk tersebut sehingga tidak dapat menimbulkan niat pembelian.

Berdasarkan hasil uji hipotesis ketiga, dapat disimpulkan bahwa $\mathrm{H}_{3}$ didukung. Maka hal ini sejalan dengan penelitian terdahulu (Tey, 2018; Rashidi, 2015; Nora, 2017). Hal ini dapat diartikan bahwa religiusitas berpengaruh positif terhadap gaya hidup tidak hanya berlaku pada gaya hidup perempuan di Iran dan gaya hidup dalam menggunakan hijab, tetapi berlaku juga pada pengguna produk Wardah di Jakarta. Dalam penelitian ini pelanggan tidak perlu merasa takut saat menggunakan produk Wardah untuk memenuhi gaya hidup mereka karena produk Wardah telah lulus uji dan kandungan di dalam produk tersebut tidak mengandung unsur-unsur yang berbahaya yang dapat merusak tubuh, termasuk bahan yang dilarang oleh agama.

Berdasarkan hasil uji hipotesis keempat, dapat disimpulkan bahwa $\mathrm{H}_{4}$ didukung dan sejelan dengan penelitian terdahulu (Tangsupwattana \& Liu, 2017; Basha dkk., 2015; Putri, 2019) yang menyatakan bahwa gaya hidup penting bagi konsumen dan akan mepengaruhi niat pembelian yang sesuai dengan gaya hidup mereka, sehingga gaya hidup berpengaruh positif terhadap niat pembelian tidak hanya berlaku pada gaya hidup konsumen generasi y di Thailand dan makanan organik, tetapi berlaku juga pada pengguna produk Wardah di Jakarta. Dalam penelitian ini pelanggan merasa bahwa produk Wardah dapat memenuhi gaya hidup mereka maka akan meningkatkan niat membeli produk tersebut tanpa banyak pertimbangan.

Berdasarkan hasil uji hipotesis kelima, dapat disimpulkan bahwa $\mathrm{H}_{5}$ didukung dan sejelan dengan penelitian terdahulu (Silva dkk., 2016; Chen, 2009; Tangsupwattana \& Liu, 2017). Hal ini dapat diartikan bahwa gaya hidup yang berpengaruh positif terhadap sikap tidak hanya berlaku pada pembelian makanan melalui internet dan gaya hidup konsumen generasi y di Thailand, tetapi berlaku juga pada pengguna produk Wardah di Jakarta. Dalam penelitian ini pelanggan merasa bahwa produk Wardah cocok digunakan dan dapat memenuhi gaya hidup mereka sesuai dengan harapan pelangganya, sehingga konsumen cenderung menyukai dan memiliki sikap yang positif terhadap produk Wardah.

Berdasarkan hasil uji hipotesis keenam, dapat disimpulkan bahwa $\mathrm{H}_{6}$ didukung dan sejalan dengan penelitian terdahulu (Suki, 2016; Rezai dkk., 2017; Souiden \& Rani, 2015) yang meyatakan bahwa sikap memiliki pengaruh yang positif terhadap niat pembelian. Maka dapat diartikan bahwa sikap berpengaruh positif terhadap niat pembelian tidak hanya berlaku pada produk ramah lingkungan dan makanan fungsional, tetapi berlaku juga pada pengguna produk Wardah di Jakarta. Dalam penelitian ini konsumen yang merasakan bahwa produk Wardah dapat memberikan manfaat untuk konsumennya dan memiliki penilaian yang baik akan menimbulkan niat pembelian pada produk Wardah. 
Berdasarkan hasil uji hipotesis ketujuh, dapat disimpulkan bahwa $\mathrm{H}_{7}$ tidak didukung dan tidak memiliki mediasi. Hal ini dapat diartikan bahwa religiusitas tidak dapat memberikan pengaruh terhadap niat pembelian melalui sikap dan berdasarkan hipotesis pertama religiusitas juga tidak mampu mempengaruhi niat pembelian secara langsung.

Berdasarkan hasil uji hipotesis kedelapan, dapat disimpulkan bahwa $\mathrm{H}_{8}$ didukung, dimana analisis mediasi tersebut merupakan partial mediation yang berarti gaya hidup mampu mempengaruhi niat pembelian dengan atau tanpa melalui sikap.

Berdasarkan hasil uji hipotesis kesembilan, dapat simpulkan bahwa $\mathrm{H}_{9}$ didukung dan memiliki analisis full mediation. Hal ini dapat diartikan bahwa religiusitas mampu mempengaruhi niat pembelian melalui gaya hidup dan sikap pengguna produk Wardah, tetapi religiusitas tidak mampu mempengaruhi niat pembelian pengguna produk Wardah secara langsung.

\section{KESIMPULAN DAN SARAN}

Berdasarkan pembahasan diatas maka dapat disimpulkan bahwa sikap dapat mempengaruhi niat pembelian. Gaya hidup mempengaruhi niat pembelian secara langsung maupun secara tidak langsung melalui sikap, tetapi religiusitas hanya dapat mempengaruhi niat pembelian secara tidak langsung melalui gaya hidup dan sikap.

Keterbatasan yang dimiliki dalam penelitian ini adalah variabel yang digunakan untuk meneliti niat pembelian produk Wardah di Jakarta hanya sebatas religiusitas, gaya hidup dan sikap dan jumlah sampel yaitu hanya 150 responden karena keterbatasan waktu dalam pengumpulan sampel. Sehingga saran untuk peneliti selanjutnya agar dapat menggunakan variabel lainnya seperti pengetahuan produk, norma subjektif, norma pribadi dan menambah sampel dan perluasan batasan wilayah.

Peneliti menyarakan kepada Wardah agar dapat terus mempertahankan faktor religiusitas dalam strategi pemasaran, karena terkenal dengan kehalalnya akan dapat membantu pelanggan mengetahui bahwa Wardah menggunakan bahan yang aman, meningkatkan iklan produknya agar dapat mengikuti trend yang dapat memenuhi gaya hidup pelanggannya dan agar sikap konsumen terhadap produk Wardah tetap baik maka Wardah harus meningkatkan kualitas produknya, sehingga dapat meningkatkan niat pembelian.

\section{REFERENSI}

Alsaad, A., Saif-Alyousfi, A. Y., \& Elrehail, H. (2021). Religiosity, idealism, and ethical consumption: the mediating effect of perceived customer effectiveness and moral obligation. Journal of Social Marketing, 11(1), 25-43. https://doi.org/10.1108/JSOCM-072020-0116

Amri, S., \& Prihandono, D. (2019). Influence lifestyle, consumer ethnocentrism, product quality on purchase decision through purchase intention. Management Analysis Journal, 8(1), 2538. https://journal.unnes.ac.id/sju/index.php/maj/article/view/26057

Azjen, I. (1991). The theory of planned behavior. Organizational Behavior and Human $\begin{array}{lrr}\text { Decision } & \text { PO(2), } & \text { 179-211. }\end{array}$ https://www.dphu.org/uploads/attachements/books/books_4931_0.pdf

Baatwah, S. R., Al-Qadasi, A. A., \& Al-Ebel, A. M. (2020). Religiosity at the top: does it interact with accounting expertise to limit real earnings management?. Managerial Auditing Journal, 35(9), 1343-1377. https://doi.org/10.1108/MAJ-12-2019-2521 
Bakar, A., Lee, R., \& Hashim, N. H. (2013). Parsing religiosity, guilt and materialism on consumer ethics. Journal of Islamic Marketing, 4(3), 232-244. https://doi.org/10.1108/JIMA-04-2012-0018

Basha, M. B., Mason, C., Shamsudin, M. F., Hussain, H. I., \& Salem, M. A. (2015). Consumers attitude towards organic food. Procedia Economics and Finance, 31, 444-452. https://doi.org/10.1016/S2212-5671(15)

Cheah, I., Teah, M., Lee, S., \& Davies, Z. (2021). Straight eye for the queer ad: Attitudes, skepticism, inferences of manipulative intent and willingness to buy. Asia Pacific Journal of Marketing and Logistics, 33(5), 1220-1238. https://doi.org/10.1108/APJML-03-2020$\underline{0124}$

Chen, M. F. (2009). Attitude toward organic foods among Taiwanese as related to health consciousness, environmental attitudes, and the mediating effects of a healthy lifestyle. British Food Journal, 111(2), 165-178. https://doi.org/10.1108/00070700910931986

Cokki, C., Soelaiman, L., \& Puspitowati, I. (2019). Transformasi digital merek-merek Indonesia dalam bentuk penempatan produk pada web series di situs web Youtube. DeReMa Jurnal Manajemen, $14(1)$, 155-170. https://pdfs.semanticscholar.org/2a1d/a0c1e88dc714615338df045cb600da85f182.pdf

Fishbein, M., \& Ajzen, I. (1977). Belief, attitude, intention, and behavior: An introduction to theory and research. Journal of Business Venturing, 5, 177-189. https://philarchive.org/archive/FISBAI

Ghozali, I. (2014). Structural Equation Modelling, metode alternative dengan Partial Least Square (PLS) (4th ed.). Semarang: Badan Penerbit Universitas Diponegoro.

Hair, J. F., Risher, J. J., Sarstedt, M., \& Ringle, C. M. (2019). When to use and how to report the results of PLS-SEM. European Business Review, 31(1), 2-24. https://doi.org/10.1108/EBR-11-2018-0203

Hoque, M. E., Hashim, N. M., \& Azmi, M. H. (2018). Moderating effects of marketing communication and financial consideration on customer attitude and intention to purchase Islamic banking products. Journal of Islamic Marketing, 9(4), 779-822. https://doi.org/10.1108/JIMA-01-2017-0005

Keni, K., Aritonang, L. R., \& Pamungkas, A. S. (2019). Purchase intention, satisfaction, interest and previous purchase behaviour. International Journal of Innovation, Creativity and Change, 5(6), 1129-1140. http://repository.untar.ac.id/id/eprint/13491

Kudeshia, C., \& Kumar, A. (2017). Social eWOM: does it affect the brand attitude and purchase intention of brands? Management Research Review, 40(3), 310-330. https://doi.org/10.1108/MRR-07-2015-0161

Lee, H. (2019). The effect of anti-consumption lifestyle on consumer's attitude and purchase intention toward commercial sharing systems. Asia Pacific Journal of Marketing and Logistics, 31(5), 1422-1441. https://doi.org/10.1108/APJML-06-2018-0218

Lin, L. Y., \& Lu, C. Y. (2010). The influence of corporate image, relationship marketing, and trust on purchase intention: the moderating effects of word-of-mouth. Tourism review, 65(3), 16-34. https://doi.org/10.1108/16605371011083503

Malhotra, N. K. (2015). Essentials Of Marketing Research. England: Pearson Educated Limited.

Memon, Y. J., Azhar, S. M., Haque, R., \& Bhutto, N. A. (2020). Religiosity as a moderator between theory of planned behavior and halal purchase intention. Journal of Islamic Marketing, 11(6), 1821-1836. https://doi.org/10.1108/JIMA-01-2019-0006

Muhamad, N., Leong, V. S., \& Isa, N. M. (2017). Does the country of origin of a halal logo matter? The case of packaged food purchases. Review of International Business and Strategy, 27(4), 848-500. https://doi.org/10.1108/RIBS-06-2017-0049 
Ngah, A. H., Garbarre, S., Jeevan, J., Salleh, N. H., \& Hanafiah, R. M. (2021). To pay or not to pay: Measuring the effect of religiosity in the ABC theory. Management Science Letters, 11(3), 795-806. https://doi.org/10.5267/j.msl.2020.10.026

Nora, L., \& Minarti, S. N. (2016). The role of religiosity, lifestyle, attitude asdeterminant purchase intention. International Multidisciplinary Conference Proceedings, 1(1), 135148. https://jurnal.umj.ac.id/index.php/IMC/article/view/1172

Putri, Y. A. (2019). Pengaruh bauran promosi dan gaya hidup terhadap minat beli pada kedai kopi serasi. Jurnal Manajemen Strategi Dan Aplikasi Bisnis, 2(2), 137-144. https://doi.org/10.36407/jmsab.v2i2.84

Rashidi, H. (2015). Lifestyle and Youth: Identifying Lifestyle among Women in Mahabad, Iran. European Online Journal of Natural and Social Sciences, 4(1), 1052-1060. http://european-science.com/eojnss_proc/article/view/4313

Rezai, G., Teng, P. K., Shamsudin, M. N., Mohamed, Z., \& Stanton, J. L. (2017). Effect of perceptual differences on consumer purchase intention of natural functional food. Journal of Agribusiness in Developing and Emerging Economies, 7(2), 153-173. https://doi.org/10.1108/JADEE-02-2015-0014

Rizkitysha, T. L., \& Hananto, A. (2020). Do knowledge, perceived usefulness of halal label and religiosity affect attitude and intention to buy halal-labeled detergent? Journal of Islamic Marketing. Advance online publication. https://doi.org/10.1108/JIMA-03-2020-0070

Rostiani, R., Toyib, J. S., \& Khoiriyah, S. (2021). Why do Muslims engage in adaptive worship behavior during the pandemic? The role of protection motives and religiosity. Journal of Islamic Marketing, 12(3), 518-542. https://doi.org/10.1108/JIMA-09-2020-0261

Selvakumar, J. J., \& Raghavan, N. R. (2017). Influence of lifestyle and attitude on online shopping. Asia Pacific Journal of Research, 1(55), 24-30. https://scholar.archive.org/work/j7z3v3clxrddjjp5wdvttrbxay/access/wayback/http://www. apjor.com/downloads/110920176.pdf

Silva, F. Q., Freire, O., Lima-Filho, D. D., Brandao, M. M., Isabella, G., \& Moreira, L. B. (2016). Intentions to purchase food through the internet: Developing and testing a model. British Food Journal, 118(3), 572-587. https://doi.org/10.1108/BFJ-09-2015-0305

Souiden, N., \& Rani, M. (2015). Consumer attitudes and purchase intentions toward Islamic banks: The influence of religiosity. International Journal of Bank Marketing, 33(2), 143 161. https://doi.org/10.1108/IJBM-10-2013-0115

Suki, N. M. (2016). Green product purchase intention: Impact of green brands, attitude, and knowledge. British Food Journal, 118(12), 2893-2893. https://doi.org/10.1108/BFJ-06$\underline{2016-0295}$

Tangsupwattana, W., \& Liu, X. (2017). Symbolic consumption and Generation Y consumers: evidence from Thailand. Asia Pacific Journal of Marketing and Logistics, 29(5), 917-932. https://doi.org/10.1108/APJML-01-2017-0013

Tariq, M. I., Nawaz, M. R., \& Awais, B. (2013). Customer perceptions about branding and purchase intention: A study of FMCG in an emerging market. Journal of Basic and Applied Scientific Research, 3(2), 127-143. https://www.academia.edu/download/34601587/Customer_Perceptions_about_Branding and_Purchase_Intention.pdf

Tey, S. E., Park, M. S., \& Golden, K. J. (2018). Religiosity and healthy lifestyle behaviours in Malaysian Muslims: The mediating role of subjective well-being and self-regulation. Journal of Religion and Health, 57(6), 2050-2065. https://doi.org/10.1007/s10943-017$\underline{0420-2}$ 
Tuhin, M. K., Miraz, M. H., Habib, M. M., \& Alam, M. M. (2020). Strengthening consumers' halal buying behaviour: Role of attitude, religiosity and personal norm. Journal of Islamic Marketing. Advance online publication. https://doi.org/10.1108/JIMA-07-2020-0220

Ustaahmetoglu, E. (2020). The influence of different advertisement messages and levels of religiosity on attitude and purchase intention. International Journal of Islamic and Middle Eastern Finance and Management, 13(2), 339-356. https://doi.org/10.1108/IMEFM-02$\underline{2019-0064}$

Wardah. (2020, November 27). Wardah, Beauty Cosmetics Indonesia. https://www.wardahbeauty.com/id

Watson, A., Alexander, B., \& Salavati, L. (2020). The impact of experiential augmented reality applications on fashion purchase intention. International Journal of Retail \& Distribution Management, 48(5), 443-451. https://doi.org/10.1108/IJRDM-06-2017-0117

Widyanto, H. A., \& Sitohang, I. A. (2021). Muslim millennial's purchase intention of halalcertified cosmetics and pharmaceutical products: The mediating effect of attitude. Journal of Islamic Marketing. Advance online publication. https://doi.org/10.1108/JIMA-04-20200117

Yang, K. C. (2004). A comparison of attitudes towards internet advertising among lifestyle segments in Taiwan. Journal of Marketing Communications, 10(3), 195-212. https://doi.org/10.1080/1352726042000181657 